\title{
PLS-SEM a 2nd generation technique: Concepts, properties characteristics and phases for its application
}

\author{
Diana Faviola Olea-Flores ${ }^{1,{ }^{*}}$, Alejandra Aldrette-Malacara ${ }^{2}$ and Luis Cuautle-Gutiérrez ${ }^{3}$ \\ 1 Universidad Popular Autónoma del Estado de Puebla (Popular Autonomous University of the State of Puebla,) Mexico. \\ ${ }_{2}^{2}$ Academic secretary. Engineering Deanship. Universidad Popular Autónoma del Estado de Puebla (Popular Autonomous \\ University of the State of Puebla), Mexico. \\ ${ }^{3}$ Faculty of Industrial and Logistics, Universidad Popular Autónoma del Estado de Puebla (Popular Autonomous \\ University of the State of Puebla), Mexico.
}

World Journal of Advanced Engineering Technology and Sciences, 2021, 03(02), 007-023

Publication history: Received on 29 September 2021; revised on 06 October 2021; accepted on 08 October 2021

Article DOI: https://doi.org/10.30574/wjaets.2021.3.2.0066

\begin{abstract}
The multivariate technique of partial least squares structural equations (PLS-SEM) considered as second generation, has become more relevant in its application in recent years in various investigations, so this article considers an descriptive research, the which presents some properties characteristic of said technique and through the application of data and values obtained from a case study shows the phases required to validate and evaluate a model with the PLSSEM technique. With the results obtained, a theoretical model is generated and proposed that could be useful for researchers who starting in the use and application of this technique.
\end{abstract}

Keywords: Structural equation modeling; SEM; PLS-SEM; Measurement models; Factor analysis

\section{Introduction}

In the existing literature, numerous studies have been carried out, which has considerably increased the number of publications on the PLS-SEM technique. Some authors as Ghasemy, Teeroovengadum, Becker \& Ringle [1] indicate that, structural equation modeling of Partial Least Squares (PLS-SEM), is a technique of multivariate data analysis in the second generation, which has been applied substantially since 2015, in explanatory studies and predictive in research, in areas such as higher education, social sciences, behavioral sciences, among others. The use of PLS_SEM allows researchers to use various advanced tools (Fimix -PLS; CTA-PLS; PLS- Predict, etc) [2]. The which give greater confidence to research by its statistical efficiency and is generated with robust and powerful software [3]; to being properly applied possible to generate significant theoretical contributions in the applied field, and also developing and testing models sophisticated [1].

Authors such as Leyva and Olague [4], indicate that among the benefits of the method or model of structural equations, it allows examining the relevant variables in parallel, as well as evaluating the theoretical model of the research and therefore examining the significance of the hypotheses in the model.

Studios conducted in different contexts, have applied the technique PLS- SEM, which has allowed researchers to perform both relevant theoretical contributions as well as the development and testing of models (some of them complex) [1]. Therefore, the objective of this study is to expose and highlight the main guidelines for developing a PLS-

\footnotetext{
* Corresponding author: Diana Faviola Olea Flores

PhD Student, Popular Autonomous University of the State of Puebla (National Autonomous Popular University of Puebla) Mexico. 
SEM analysis through a case study. With the results of the analysis carried out, it is expected to develop a model for researchers who are starting to use this technique.

The article is structured in two phases: the first presents a brief introduction to the study, with basic and fundamental aspects and concepts of the technique and the second shows the process to validate a research model with the PLS-SEM technique. Starting from this, from the proposed theoretical model of e-SQM derived from a systematic review of the eSQ literature [5], and from the data and values obtained from it.

\subsection{Background, Definitions, Characteristics and Fundamental Concepts used in PLS-SEM}

The origin of the algorithm or technique of structural equations of partial least squares (PLS) as indicated [4], is generated in its final version in 1977 by the Norwegian research econometrician Herman Wold, having its first applications in economics. Likewise, authors such as Ghasemy et al. [1], indicate that this technique was later complemented by Lohmöller $[6,7,8]$, which is an approach that is based on compounds for SEM , and PLS- SEM combines indicators linearly with what creates compound variables [6], therefore, researchers, consider it as substitutes for the concepts they study .

According to Salgado and Espejel [9], models structural equations are evaluated with the least squares technique partial (PLS) as indicated by $[10,11]$, and are considered as technical or analytical models multivariate of second generation $[12,13]$.

For some authors like Medina [14], indicate that, authors like [15, 16], the structural equation models that have been found in the academic literature as SEM is the abbreviation for Structure to the Equation Model, correspond in to a multivariate statistical analysis technique or method, by means of which causal relationships and effects between various variables can be estimated, which can be latent or observable, and for which a set of mathematical equations are used, which make graphic representation possible of the relations proposed by the theory.

PLS-SEM has been used in various disciplines, which we can see in Table 1, which indicates the periods and the amount of investigations in which they have been applied.

Table 1 PLS-SEM in various disciplines

\begin{tabular}{l|c|c|c|}
\hline Business discipline & Period & Number of studies & Reference \\
\hline Marketing & $1981-2010$ & 204 & {$[17]$.} \\
\hline Strategic management & $1981-2010$ & 37 & {$[18]$.} \\
\hline Management information systems & $1992-2001$ & 65 & {$[19]$.} \\
\hline Management information systems & $2010-2014$ & 57 & {$[20]$.} \\
\hline International business & $1990-2013$ & 45 & {$[21]$.} \\
\hline Human resource management & $1985-2014$ & 114 & {$[22]$.} \\
\hline Operations management & $2000-2011$ & 42 & {$[23]$.} \\
\hline Supply chain management & $2002-2013$ & 75 & {$[24]$.} \\
\hline Accounting & $2005-2011$ & 20 & {$[25]$.} \\
\hline Accounting & $1980-2013$ & 37 & {$[26]$.} \\
\hline Tourism & $2000-2014$ & 44 & {$[27]$.} \\
\hline Hospitality & $2001-2015$ & 29 & {$[28]$.} \\
\hline Hospitality and Tourism & $2000-2017$ & 206 & {$[29]$.} \\
\hline
\end{tabular}




\subsubsection{Fundamental concepts used in PLS-SEM}

According to Salgado and Espejel [9], when it comes to causality, it refers to why a phenomenon is generated and under what conditions it happens [31].

For their part, Hair et al. [32], indicate that there are two types of variables in SEM modeling:

\section{Latent variable}

Also referred to in the literature as independent, exogenous, etc. and they are the ones that explain other constructs [32]. In other words, it is the characteristic ( $\mathrm{s}$ ) that one would like to measure but cannot be observed [33], that is, it is not possible to measure them directly (for example, depression, intelligence, etc.), so variables are required. Observed to be measured [34].

\section{Observed variable}

Also known as indicators, dependent, endogenous are the ones that are being explained [32]. That is, it can be measured directly, such as age, height, weight, etc. [3. 4].

\subsubsection{Properties / Characteristics and Advantages of PLS-SEM}

Authors such as Leyva and Olague [4], state that, in the characteristics of the technique of structural equations is $n$ the construction of research models, in which, from theoretical concepts system (latent, independent, exogenous) unobservables originate and with the modification of empirical concepts in indicators (dependent, endogenous). The two are related and therefore by means of hypotheses they are represented graphically by trajectory diagrams [2].

Also, Medina [14 ] indicates, that the analysis models of the first generation encompasses linear regression, which cover only a level of relationship between the variables [35], while the second generation models includes the structural equation, which makes it possible to mold relationships between various constructs in parallel, build unobserved variables and create relationships between predictors and variables, among others [36].

For his part Martínez and Fierro [3], point out that the PLS technique can be used in explanatory research (confirmatory) and predictive (exploratory) [37, 32]. Therefore, according to [38], it can be emphasized that an explanatory model is generated in order to check the causal hypotheses themselves that indicate how and why a certain empirical phenomenon occurs. Whereas a predictive model refers to the construction and evaluation of a model, the purpose of which is to predict new or future observations or panoramas, that is, its purpose is to generate accurate predictions of new observations [3].

The application of PLS-SEM as indicated Medina [14], specifically allows to confirm theory and propose possible relationships between variables as well as propose proposals for subsequent links between constructs [12]. Similarly, the SEM originated from PLS make up a procedure by means of which the order of the constructs can be determined, thereby obtaining predictive values for the latent variables generated [12].

For their part, Hair, Hult, Ringle and Sarstedt [39], indicate that SEM is a mixture generated from two powerful statistical approaches, one is the exploratory factor analysis and the second structural route analysis in such a way that it generates the simultaneous evaluation of the model measurement and structural model [25]. Likewise, the explained variance generated in the dependent variable (s) increases using SEM than multiple regressions, due to the fact that it presents direct and indirect effects [25].

Meanwhile, Salgado and Espejel [40], indicate that the models PLS-SEM aim to predict the latent variables which maximize the explained variable $\left(\mathrm{R}^{2}\right)$ of the dependent variables [41], whose characteristics are mentioned by [42], and they are the following: 1 . The PLS-SEM models are aimed at prediction having the analysis of variances or components as a means. 2. A latent variable is made up of a linear combination of its own manifest variables; 3 . The relationship between a latent variable and its manifest variables is reflective and formative; 4. the difficulty of the model is great (example 10 latent variables 100 manifest variables); 5 . you can have small samples but the range that is advised from 30 to 100 cases; 6 . The application of the theoretical is flexible, which generates they are known as "soft modeling"; 7. It is through algorithms the treatment or management of lost data. Importantly, the methodology used generically combines PLS principal component analysis and analyse is regression multiple features. [40].

Likewise Leyva and Olague [4], they indicate that one of the most relevant advantages of the structural equations in the use of PLS is the way it performs the regression in the estimation of the measurement model. While 
Mateos [43], indicating that regression is used minimum partial square to reduce dimensions of the group of explanatory variables. For several years the principal component technique or methods have been used, the purpose of which is to generate a new group of variables as a linear result of the initial ones, but eliminating multicollinearity. If this method is applied for a regression, it is known as principal components regression (which is also known by its acronym in English as Principal Components Regression or PCR), because this analysis is performed only on the independent variable but neither ensures nor recommends using the principal components technique to explain the dependent variable. In PLS, responding to this situation, the regression in this method is trying to obtain latent variables in such a way that it covers most of the variation of the observed independent variables in such a way that they can be used for the modeling of the variable dependent [4].

For his part, Sarstedt et al. [30], state that among the advantages of PLS-SEM, which have contributed to increasing its diffusion in the last ten years; are any features as the capacity of the technology for handling complex models with minimal data [32], the valuation models certain measurement formatively [44], and specifies generation of latent models with variable scores [45]. Also authors like [46, 47, 48], indicate that in a number of publications has been highlighted that PLS_SEM interesting for research and applied science by the test of hypothetical relationships having a predictive approach in estimating the m model [30].

Table 2 Main multivariate methods

\begin{tabular}{|c|c|c|}
\hline Technique & $\begin{array}{l}\text { Mainly exploratory } \\
\text { (predictive) }\end{array}$ & $\begin{array}{l}\text { Mainly confirmatory } \\
\text { (evidential or explanatory) }\end{array}$ \\
\hline \multirow[t]{4}{*}{ First generation techniques } & Cluster analysis & Variance analysis \\
\hline & Exploratory factor analysis & Logistic regression. \\
\hline & Multidimensional scaling. & Multiple regression. \\
\hline & & Confirmatory factor analysis \\
\hline Second generation techniques & PLS-SEM & CB-SEM \\
\hline
\end{tabular}

\subsection{Criteria to consider for using PLS Shem}

Two methods are most commonly used and $n$ modeling structural equation (SEM), with relevant approaches, as affirmed-indicated [3], the first considered approach is based on analysis of covariance structures (CB for short English) which is suggested for use when looking to contrast theories, hypothesis tests or in the design of new theories which are supported by the theory of research carried out; the second one that is referred to partial minimum squares (PLS for its acronym in English) based on the analysis of variance.

Some criteria proposed by Hair et al. [49], which can support the investigations in opting for the use of PLS are:

\section{Research objective}

- If the objective is to predict target or key constructs.

- Whether the type of research being conducted is exploratory or an expansion of an existing structural theory

- Measurement Model Specifications

- If the constructs of the measurement model are formative and are part of the structural model

- Structural model

- If the structural model contains many constructs with many indicators (it is complex)

- Sample size

- If the sample size is considerably small. With large data sizes it is possible to use it as long as a large number of indicator variables are available for the measurement of latent constructs [49].

- The sample size required in PLS-SEM must be equal to or greater than what is indicated below : 1) Ten times the largest number of formative indicators used to measure a construct or 2) Ten times the largest number of trajectories directed to the latent construct this is specifically in the structural model. [49].

- If the data is abnormal up to a certain limit, use PLS [49]. In this regard, [3], they highlight that asymmetry and kurtosis values with results greater than one are a sign of highly non-normal values. 


\subsection{Models Measurement}

Authors such as, Medina [14], indicates that for Máynez [50], the path models that are generated by PLS and the models generated from the structural equation models as indicated by Hair et al. [39], are made up of two elements:

- The structural model (also called internal model) which graphically presents the structural routes between the constructs and the measurement models (also called external), which represent the relationships between each construct, that is, from latent variable to indicator or associated variables . For which it should be noted that there are two types of variables: the so-called indicators, exogenous that explain other constructs, and those that are being explained, called latent or endogenous variables [39].

- The measurement model (also called external model) this is formed according to the type of measurement, which can be formative or reflective; For this, arrows are used to link the constructions in the model. If the constructions are measured with formative indicators, these will be represented or schematized with arrows that go from the indicator to the latent construct [44]. On the contrary, if the effects are reflective, the variables will be represented by arrows that go from the construct to the indicator [39].

\subsubsection{Formative, reflective measurement models / Conceptual differences}

In formative measurement are constructs or indicators which cause a latent variable, so that a change in said non generates varying a change in its indicators (Valdivieso and Carlos Eduardo) [51]. Similarly [3], point out that the formative models are latent construct-variables formed by measurement indicators, which are the cause or antecedent of the construct $[51,52]$, which means that each indicator is a dimension of the meaning of the latent variable [3].

While a reflective model is one in which a change in the latent variable (not observable) will be reflected in a change in all its indicators [51]. For his part [3], refer that a reflective model is estimated as a measurement model in which the indicators of the latent variable compete with each other, which represents characteristics of the latent variable. Therefore, the causal relationship is presented from the latent variable to the indicators and when a change is generated in it, it will be reflected in all its indicators.

The difference between both models, as indicated [51, 3], is found in the causal relationship between the latent variable and its indicators.

\section{Methodology for the use of PLS-SEM}

The PLS-SEM methodology as indicated by Raza, Rather, Iqbal , \& Bhutta [54], has been applied in recent studies by various authors such as Hair et al., Sarstedt and Mooi; Ying et al., Farrukh et al. [55, 56, 57.58].

With the above and according to the methodology suggested by Hair et al. [39] , which has been adapted by several authors in various investigations, and in which they agree on nine phases for the use of the technique. Which below are mentioned and briefly described according to [3]: a) Determination of the structural model. b) Determination of the measurement model. c) Data collection and analysis. d) Estimation of the model. e) Evaluation of formative measures, f) evaluation of reflective measures g) evaluation of the structural model, h) advanced analysis, i) interpretation of results $[3,49]$.

- Determination of the structural model. In the first stage of the project or research that is being carried out, it is required to graphically generate a diagram that shows the connections of the variables, which start and are based on the theory and that show the relationship of the hypotheses to be tested. The model is composed of two elements: 1st structural model (also known as internal model in PLS_SEM) which shows the relationships between the latent variables; It should be noted that two fundamental aspects can be perceived in the graphic representation: the order of the constructs or variables and the relationship between them, which will be shown in the hypotheses considering the theory considered to be tested, additionally that the variables can be visualized latent and observable. $2^{\circ}$ The measurement model, which exposes the relationships between the latent variables and their indicators [3].

To represent the structural diagrams as mentioned by Manzano [34], it is essential to represent them graphically. A square is used to symbolize the observed variable, a circle or ellipse for the latent variable; to represent an association it will be with a unidirectional arrow and if a correlation is required it will be with a bidirectional arrow.

- Determination of the measurement model. It is essential to differentiate the measurement models themselves that can be considered as: formative and reflective models, therefore, the causal order of the latent variables, 
their indicators and their causes are of vital importance. Having a specific measurement model formally exposes the validity of the latent variable considered in the study $[3,55]$.

- Data collection and analysis. The data collection is linked to the sample size, population, type of sampling and the measurement instrument (questionnaire, interview, etc.) established to obtain data that was used to obtain the same information that once the information is completed, it must be exported to PLS-SEM to be used for further analysis [55].

- Estimation of the model. In the PLS-SEM software menu, the PLS algorithm (model estimation) is calculated in which the results will be shown graphically - schematized by means of a path model in which the factorial loads, the regression coefficients standardized or path coefficients and the $\mathrm{R}^{2 .}$ [3].

- $\quad$ evaluation of formative and reflective measures

For the evaluation of reflective models as indicated by Hair et al. [39], and Martínez \& Fierro [3]; It is performed by: 1st, internal consistency provides the reliability of the construct, it is validated with Cronbach's alpha and composite reliability, the latter being the most recommended since it considers the differential weights). 2 nd, convergent validity, which refers to the group of indicators that represent a single underlying construct, is obtained by examining the external loads of the indicators to determine the average variance extracted (AVE) of each construct. The main rule that should be considered that the AVE $>=0.50$. 3rd Discriminant validity shows that a construct is unique from the other constructs; For this validity, it is necessary to consider three criteria, that of Fornell-Larcker (1981), that of crossed loads and the HTMT matrix [3].

For the formative models, it is necessary to calculate the convergent validity, collinearity between indicators and significance and relevance of the weights [39, 3].

- evaluation of the structural model, in a general way as indicated [39, 3]. For the estimation of the structural model, the use of Determination coefficients (R2), Predictive relevance (Q2), Size and significance of the path coefficients, Size of effects $\mathrm{f} 2$, Size of effects q2 is recommended.

\section{Results and discussion}

\subsection{PLS-SEM methodology: Applied to an e-SQM model study case}

To show the methodology used for this technique, the SmartPLS 3 software was used, as well as information obtained from the online survey applied for the investigation of the e-SQM model, derived from the model proposed by [5].

Following the methodology suggested by some authors such as Hair et al. [49-39]; Martínez and Fierro [3]. In the first phase, a theoretical model is generated which is derived from the literature review, and where the content is validated; likewise, the latent variables or constructs are proposed. Therefore, considering the information obtained for this model, 7 variables were established Efficiency, Privacy, Fulfillment / Reliability, Responsiveness, Contact, Guaranty, CSEM.

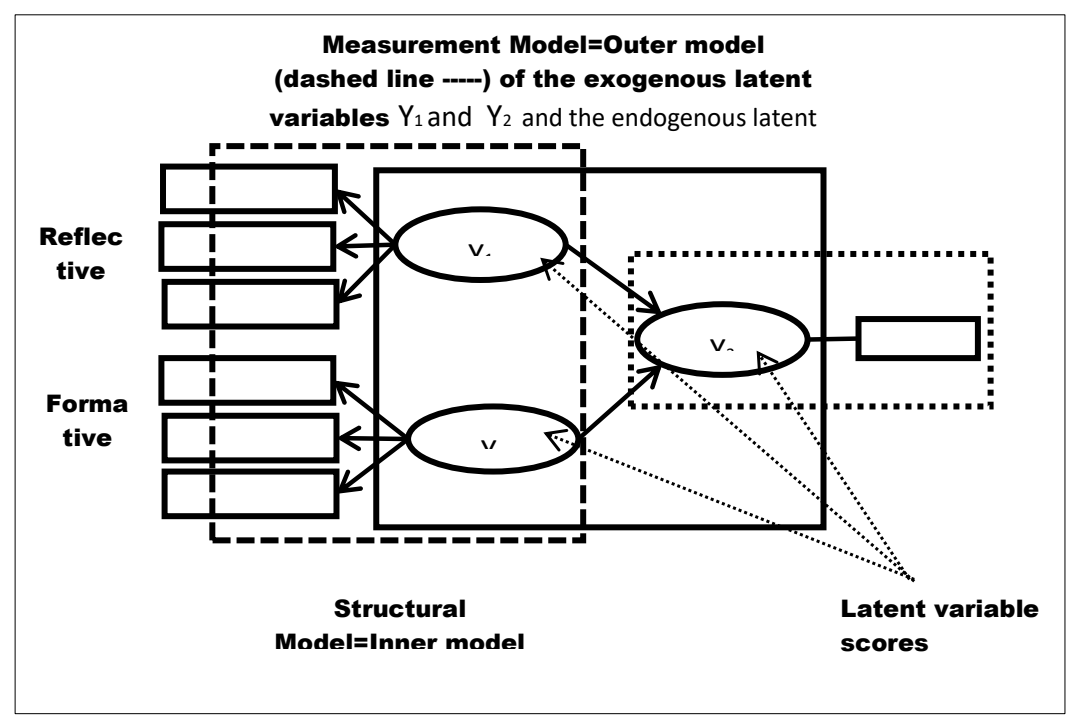

Figure 1 Reflective and formative models; Source: Own preparation with information of [39]. 
In the second phase, it is necessary to establish the indicators or observable variables. In the same way, it is required in this phase to determine if the model is formative or reflective. (Figure 1) For the case that is being exemplified reflective.

In the third phase, it is required to generate a database of the information obtained from the instrument that was applied, it is crucial that the generated file be saved with a .cvs extension limited by commas, which will be opened or exported to SmartPLS. In figure 2, you can see how the information is distributed.

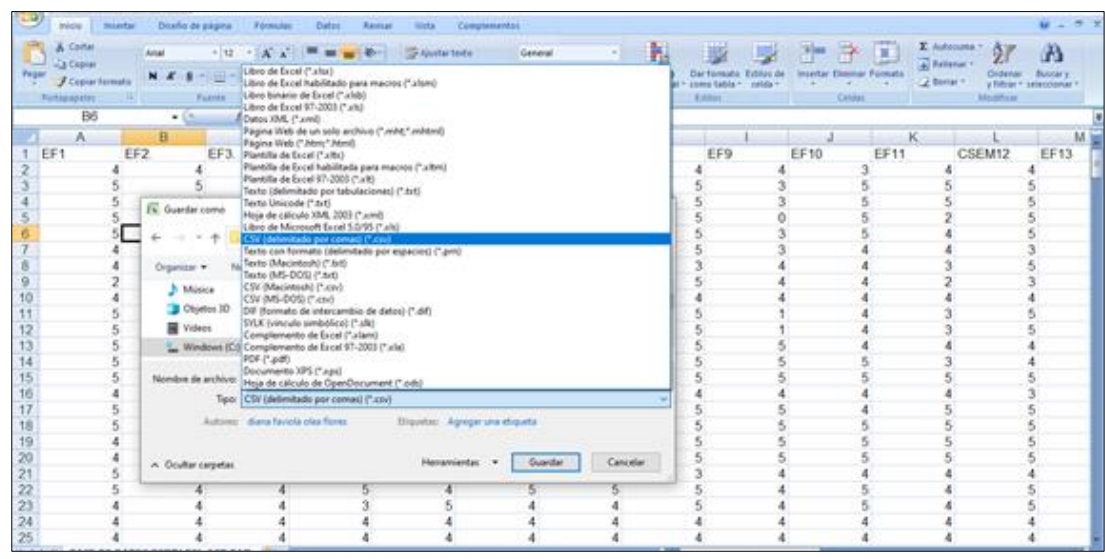

Figure 2 Information distribution; Source: Own preparation

When starting the session in the PLS software already with the database loaded, it is required as the first instance to generate the proposed model of the research and that has been carried out according to the theoretical model, for this it is necessary to first generate the latent variables themselves that will be connected with arrows using the connector found in the menu at the top without forgetting to indicate the direction of the arrow which indicates whether the model is formative or reflective. Subsequently, each latent variable is assigned its items / indicators, for which in the lower left box there is a list of indicators for each variable, which must be dragged to the corresponding variable so that the software assigns its indicators to each one. or items (Figure 3).

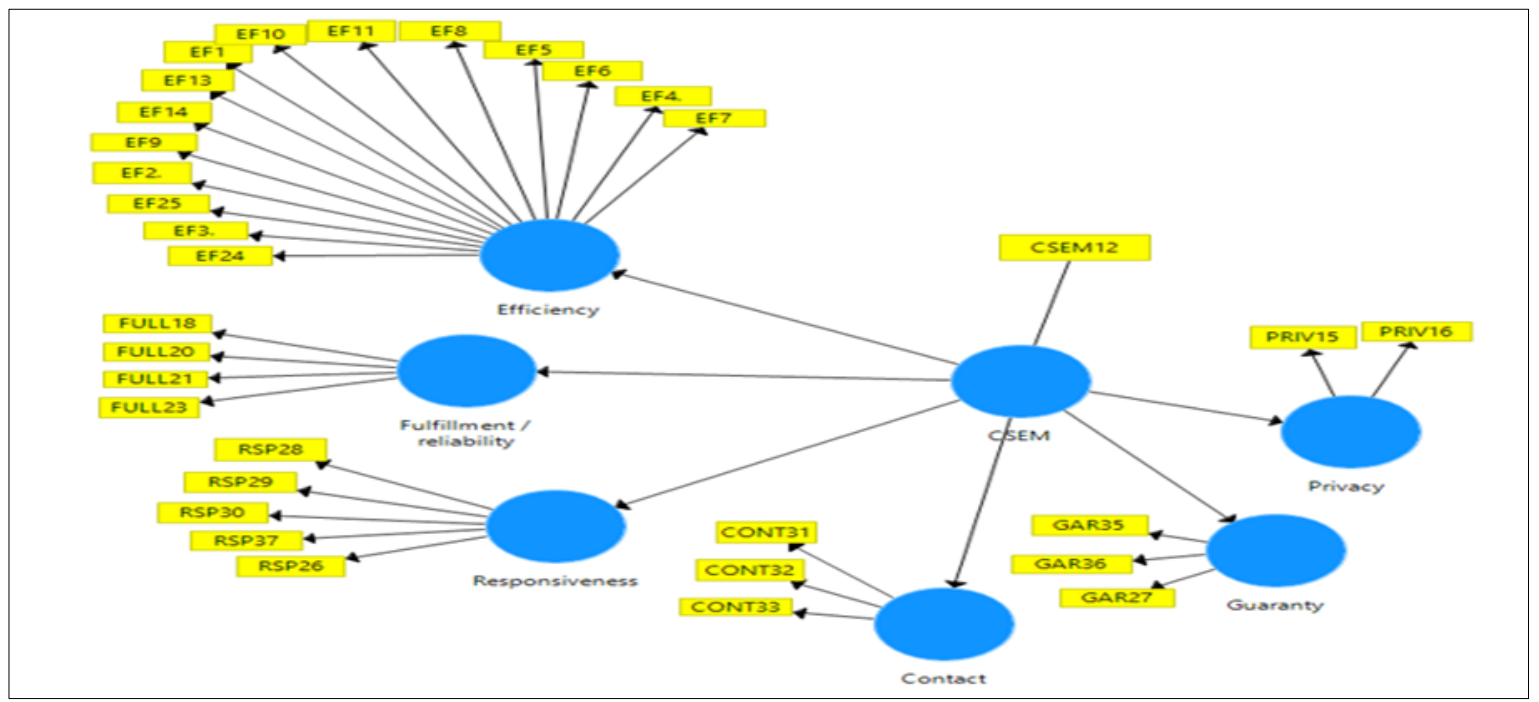

Figure 3 Research model; Source: Own preparation

In the fourth phase the estimation of the model is calculated or carried out in the Algorithm, for which in the upper part of the main menu there is the option calculate that will show us the results and as indicated above, we will be presented with the factorial loads, the coefficients Regression Path and standardized ones, as well as $\mathrm{R}^{2}$. (Figure 4). 


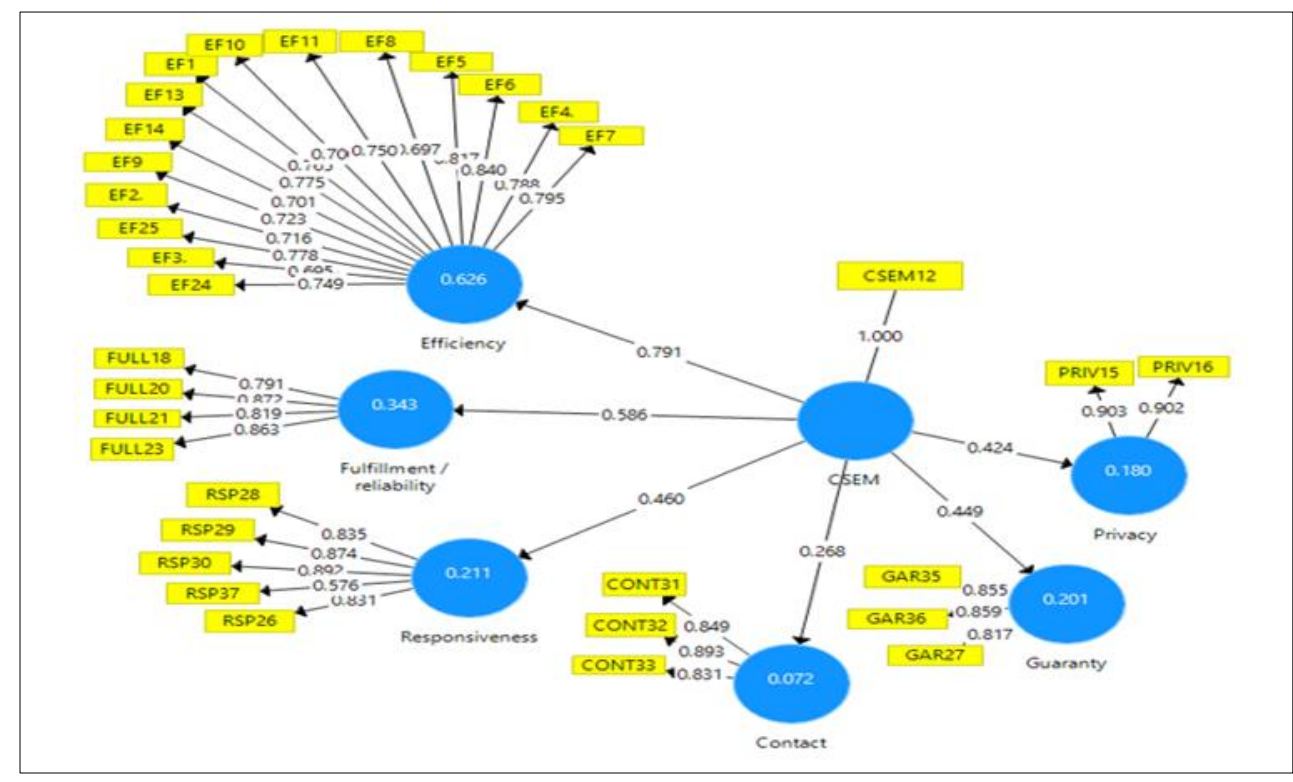

Figure 4 Model estimation; Source: Own preparation

The fifth phase requires the evaluation of the measurement / research model that, as indicated by Hair et al., [49], it is essential to distinguish and ensure whether the model is reflective or formative. For reflective models, they must be evaluated according to their reliability of internal consistency, convergent validity and discriminant validity.

Regarding internal consistency (Table 3), it provides the reliability of the construct; to evaluate the alpha used Cronbach and composite reliability which is considered more appropriate latter and requires values from 0.60 to 0.70 for exploratory research and from 0.70 to 0.90 for investigations stages more outposts considered satisfactory [59].

Table 3 Internal consistency results

\begin{tabular}{|l|c|c|l|l|c|l|}
\hline & & & & & \\
\hline Construct & $\begin{array}{l}\text { Cronbach's } \\
\text { alpha }\end{array}$ & Criterion & Outcome & $\begin{array}{l}\text { Composite } \\
\text { reliability (CR) }\end{array}$ & Criterion & Outcome \\
\hline CSEM & 1,000 & $0-1$ & satisfactory & 1,000 & .07 to .09 & trustworthy \\
\hline Contact & 0.821 & $0-1$ & satisfactory & 0.893 & .07 to .09 & trustworthy \\
\hline Efficiency_ & 0.939 & $0-1$ & satisfactory & 0.947 & .07 to .09 & trustworthy \\
\hline $\begin{array}{l}\text { Fulfillment } \\
\text { reliability_ }\end{array}$ & 0.857 & $0-1$ & satisfactory & 0.903 & .07 to .09 & trustworthy \\
\hline Guaranty & 0.798 & $0-1$ & satisfactory & 0.881 & .07 to .09 & trustworthy \\
\hline Privacy & 0.772 & $0-1$ & satisfactory & 0.898 & .07 to .09 & trustworthy \\
\hline Responsiveness_ & 0.884 & $0-1$ & satisfactory & 0.920 & .07 to .09 & trustworthy \\
\hline
\end{tabular}

The convergent validity as indicated Harahap et al. [60], allows to verify that the constructs that are expected to be related are really related; This validity is obtained if a high correlation is confirmed between the items that measure the same construct; It can be evaluated by means of various methods, including the AVE (Average variance extracted, whose value is required $>0.50$ ), and with the Reliability of the construct as indicated [3]; with which the consistency of its indicators can be verified, which means the simple correlations of the indicators with their construct; It is obtained by evaluating the factorial loads or weights $(\chi)$. Likewise, they indicate that it is of vital importance to consider as adequate factorial loads those greater than 0.707 as indicated by $[61,49]$, so that items with loads less than this range have to be eliminated and therefore again estimate the model to obtain the results with these settings [3]. (See table 4). 
Table 4 Convergent validity results

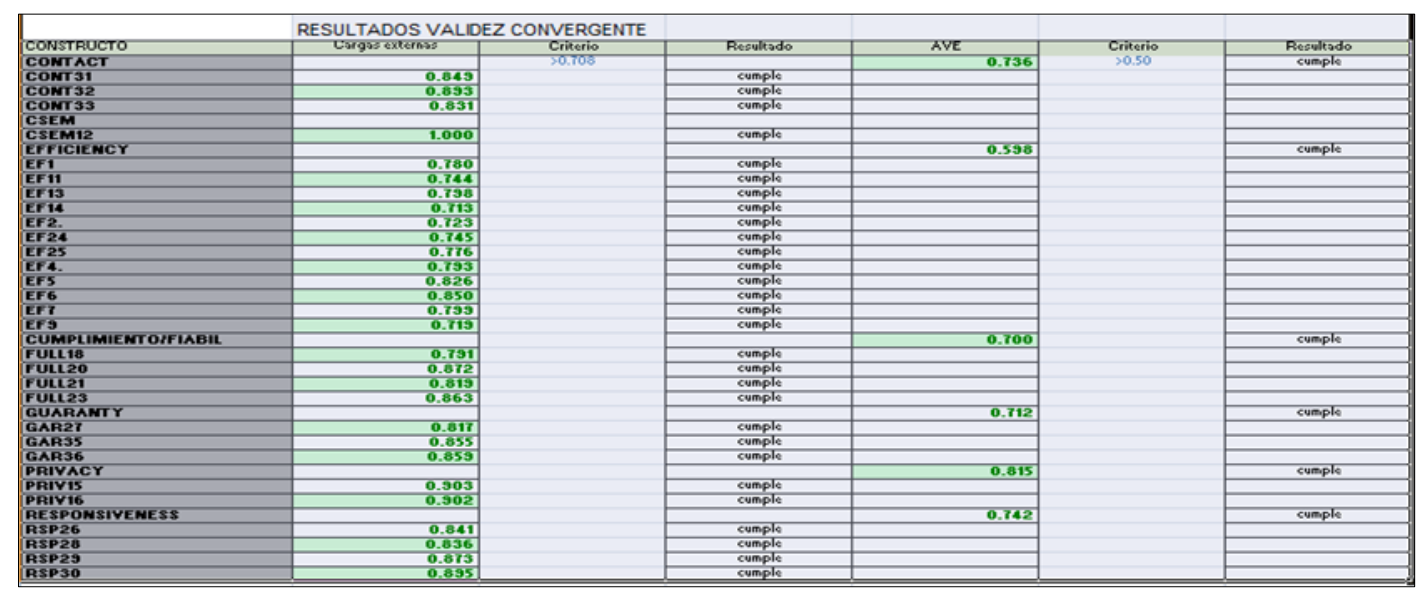

Source: Own preparation

Regarding the discriminant validity, it indicates according to Hair et al. [62], that a construct is empirically uniquedifferent from the other construct of the model, that is to say that each construct captures a unique phenomenon and that no other means what that is. To evaluate the discriminant validity, the following are used: 1st Fornell and Larcker criterion in which the square root of the AVE of each latent construct must be greater than the correlation it presents with some other construct. 2nd Cross loads. The loads of an indicator should be higher than with all the loads of the latent variables [3],

3rd Heterotrait-Monotrait Ratio Matrix (HTMT) in which it is validated that the correlations between the indicators that measure the same construct are greater than the correlations that measure different constructs [3]. For this, it is required that the value obtained is $<1$, some authors consider 0.90 .

Table 5 Summary of Results

\begin{tabular}{|c|c|c|c|c|c|c|}
\hline \multirow{3}{*}{ LATENT VARIABLE } & \multirow{3}{*}{ Abrev } & \multicolumn{2}{|c|}{$\begin{array}{l}\text { Reliability } \\
\text { consistency }\end{array}$} & \multicolumn{2}{|c|}{$\begin{array}{l}\text { Convergent } \\
\text { validity }\end{array}$} & \multirow{3}{*}{$\begin{array}{l}\text { Discriminating validity } \\
\text { HTMT Confidence interval } \\
\text { does not include } 1\end{array}$} \\
\hline & & \multirow{2}{*}{ 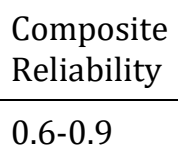 } & \multirow{2}{*}{$\begin{array}{l}\text { Alpha Cronbach } \\
0.6-0.9\end{array}$} & \multirow{2}{*}{$\begin{array}{l}\text { Loads } \\
>0.7\end{array}$} & \multirow{2}{*}{$\begin{array}{l}\text { bird } \\
>0.5\end{array}$} & \\
\hline & & & & & & \\
\hline CSEM & CSEM12 & 1,000 & 1,000 & 1,000 & 1,000 & COMPLIES \\
\hline \multirow[t]{3}{*}{ Contact } & CONT31 & 0.893 & 0.821 & 0.849 & 0.736 & COMPLIES \\
\hline & CONT32 & & & 0.893 & & \\
\hline & CONT33 & & & 0.831 & & \\
\hline \multirow[t]{9}{*}{ Efficiency } & EF1 & 0.947 & 0.939 & 0.780 & 0.598 & COMPLIES \\
\hline & EF11 & & & 0.744 & & \\
\hline & EF13 & & & 0.798 & & \\
\hline & EF14 & & & 0.713 & & \\
\hline & EF2. & & & 0.723 & & \\
\hline & EF24 & & & 0.745 & & \\
\hline & EF25 & & & 0.776 & & \\
\hline & EF4. & & & 0.793 & & \\
\hline & EF5 & & & 0.826 & & \\
\hline
\end{tabular}




\begin{tabular}{|c|c|c|c|c|c|c|}
\hline & EF6 & & & 0.850 & & \\
\hline & EF7 & & & 0.799 & & \\
\hline & EF9 & & & 0.719 & & \\
\hline \multirow{4}{*}{$\begin{array}{l}\text { Fulfillment } \\
\text { reliability_ }\end{array}$} & FULL18 & 0.903 & 0.939 & 0.791 & 0.700 & \multirow[t]{2}{*}{ COMPLIES } \\
\hline & FULL20 & & & 0.872 & & \\
\hline & FULL21 & & & 0.819 & & \\
\hline & FULL23 & & & 0.863 & & \\
\hline \multirow[t]{3}{*}{ Guaranty } & GAR27 & 0.881 & 0.798 & 0.817 & 0.712 & \multirow[t]{2}{*}{ COMPLIES } \\
\hline & GAR35 & & & 0.855 & & \\
\hline & GAR36 & & & 0.859 & & \\
\hline \multirow[t]{2}{*}{ Privacy } & PRIV15 & 0.898 & 0.772 & 0.903 & 0.815 & \multirow[t]{2}{*}{ COMPLIES } \\
\hline & PRIV16 & & & 0.902 & & \\
\hline \multirow[t]{4}{*}{ Responsiveness_ } & RSP26 & 0.920 & 0.884 & 0.841 & 0.742 & \multirow[t]{2}{*}{ COMPLIES } \\
\hline & RSP28 & & & 0.836 & & \\
\hline & RSP29 & & & 0.873 & & \\
\hline & RSP30 & & & 0.895 & & \\
\hline
\end{tabular}

\subsection{Evaluation model structural}

Table 6 Internal model VIF results

\begin{tabular}{|c|c|c|c|c|c|c|c|}
\hline & CSEM & Contact & Efficiency_ & $\begin{array}{l}\text { Fulfillment } \\
\text { / } \\
\text { reliability_ }\end{array}$ & Guaranty_ & Privacy & Responsiveness \\
\hline CSEM & & 1,000 & 1,000 & 1,000 & 1,000 & 1,000 & 1,000 \\
\hline \multicolumn{8}{|l|}{ Contact } \\
\hline \multicolumn{8}{|l|}{ Efficiency_ } \\
\hline \multicolumn{8}{|l|}{$\begin{array}{l}\text { Fulfillment / } \\
\text { reliability_ }\end{array}$} \\
\hline \multicolumn{8}{|l|}{ Guaranty_ } \\
\hline \multicolumn{8}{|l|}{ Privacy } \\
\hline Responsiveness_ & & & & & & & \\
\hline
\end{tabular}

In the sixth phase, it is necessary to consider first, that the previously revised model, which in this case study is reflective, meets the validity and reliability criteria. If yes-comply and be positive it continues with evaluation of the results of the structural model, which allows determining the ability of the model to predict one to or more target structures [63]. From according to Hair et al., [49], recommends evaluation and assessment of 5 precepts-procedures: 1. Collinearity assessment, 2. Path Coefficients; 3 . Coefficients of determination ( ${ }^{2}$ value), 4 . Effect size $\mathrm{f}^{2}$.

5. Blindfolding and predictive relevance $\mathrm{Q}^{2}$ and Effect size $\mathrm{q}^{2}$.

As for the collinearity evaluation as indicated Martínez and Fierro [3], it arises when signs of multicollinearity are found, that is, when two indicators are highly correlated; A test that can be carried out to verify it is using the VIF (variance inflation factor) for which VIF values $>5$ are considered with a tolerance $<.20$. Likewise [63], indicates that the collinearity between the latent variables is determined considering the following guidelines: VIF $>5$ indicates a probable collinearity problem, according to Hair, Ringle \& Sasrsted [49]. VIF> 3 indicates a 
probable collinearity problem [64]. Likewise (Ibid.) Indicates that the ideal values $1.49,1.56$, therefore, in the present study values of 1.00 are obtained, which indicates that it is below the ideal values but meets the specification $<5$, it is also within of the specified tolerance values, therefore it is considered that there is no collinearity problem between the latent variables.

\subsubsection{Path Coefficient}

The Path coefficient, also known as standardized regression coefficients, of trajectories; associates the latent variables in the structural model, likewise exposes the relationships of the hypotheses or the relationship strength of the research model, as indicated [3], who highlight the importance of 3 relevant aspects to consider and estimate to know if a coefficient is significant: the algebraic sign, the magnitude and the statistical significance. The algebraic sign refers to and corresponds to the one indicated in the hypothesis; Therefore, if it is contrary to that established, it will not allow to endorse-support-defend it. Regarding the magnitude of the path coefficients, it is considered established and defined values in a range between -1 and +1 , so the higher the value of the coefficient, the greater the relationship between constructs, and the closer to 0 , the weaker the relationship. as well as low values close to 0 are considered not significant. Similarly, the significance or level of significance is evaluated with t-student and with p-value which comes from bootstrapping (it evaluates if the paths-trajectories between variables is viable). In the $t$ statistics, the score obtained indicates an important influence of the independent variables on the dependent ones, that is, it examines the relationships of the constructs, therefore, the values usually applied in the two-tailed test are 1.65 (10\% significant level and $<1.96$ ( $5 \%$ significant level) [65], so if the value of $t$ is greater than the critical value of $t$, the coefficient is considered to be below the threshold, therefore, The distribution is not considered reliable and therefore the hypotheses are not tested. Likewise, the "p" value is used to evaluate the level of significance, with which the score is examined, therefore, if we take into account the level of significance of 5\%, the value of p must be less than 0.05 [63].

Table 7 Path Coefficients

\begin{tabular}{|l|c|c|c|}
\hline & $\begin{array}{l}\text { Path Coefficient } \\
\text { (Standardized } \boldsymbol{\beta} \text { ) }\end{array}$ & $\begin{array}{c}\text { Statistics t ( O / } \\
\text { STDEV |) }\end{array}$ & P Values \\
\hline CSEM -> Contact & 0.268 & 4,321 & 0.000 \\
\hline CSEM -> Efficiency_ & 0.768 & 21,501 & 0.000 \\
\hline $\begin{array}{l}\text { CSEM -> Fulfillment / } \\
\text { reliability_ }\end{array}$ & 0.586 & 10,360 & 0.000 \\
\hline CSEM -> Guaranty_ & 0.449 & 7,953 & 0.000 \\
\hline CSEM -> Privacy & 0.424 & 6,003 & 0.000 \\
\hline CSEM -> Responsiveness_ & 0.471 & 7,945 & 0.000 \\
\hline
\end{tabular}

Table 8 Path coefficient

\begin{tabular}{|c|c|c|c|c|c|c|c|}
\hline & $\begin{array}{l}\text { Path Coefficient } \\
\text { (Standardized } \beta \text { ) }\end{array}$ & Statistics t & $\begin{array}{l}\text { Critical } \\
\text { value }\end{array}$ & $\begin{array}{l}\text { Statistically } \\
\text { significant? }\end{array}$ & $\begin{array}{l}\mathbf{P} \\
\text { Values } \\
\end{array}$ & $\begin{array}{l}\text { Critical } \\
\text { value } \\
\end{array}$ & $\begin{array}{l}\text { Statistically } \\
\text { significant? }\end{array}$ \\
\hline CSEM -> Contact & 0.268 & 4,321 & 1.96 & YES & 0.000 & .05 & YES \\
\hline $\begin{array}{ll}\text { CSEM } & -> \\
\text { Efficiency_ } & \\
\end{array}$ & 0.768 & 21,501 & 1.96 & YES & 0.000 & .05 & YES \\
\hline $\begin{array}{lr}\text { CSEM } & -> \\
\text { Fulfillment } & / \\
\text { reliability_ } & \\
\end{array}$ & 0.586 & 10,360 & 1.96 & YES & 0.000 & .05 & YES \\
\hline $\begin{array}{ll}\text { CSEM } & -> \\
\text { Guaranty_ } & \\
\end{array}$ & 0.449 & 7,953 & 1.96 & YES & 0.000 & .05 & YES \\
\hline CSEM -> Privacy & 0.424 & 6,003 & 1.96 & YES & 0.000 & .05 & YES \\
\hline $\begin{array}{l}\text { CSEM -> } \\
\text { Responsiveness }\end{array}$ & 0.471 & 7,945 & 1.96 & YES & 0.000 & .05 & YES \\
\hline
\end{tabular}


The results found in the table indicate the significance values of all the constructs, as well as the relationship between constructs, with which it was found that the t statistic is significant, with a good relationship of all the constructs, highlighting that the relationship The strongest is CSEM -> Efficiency (0.768), followed by CSEM -> Fulfillment / reliability (0.586), with a medium ratio is CSEM $\rightarrow$ Responsiveness (0.471), CSEM -> Guaranty (0.449) and the lowest CSEM - > Contact (0.268). Likewise, regarding the level of significance, the results indicate a probability score of 0.000 below the indicated one of 0.05 , which allows us to conclude that the relationship under consideration is positive and significant.

\subsubsection{Coefficients of determination ( $R^{2}$ value).}

The evaluation of $\mathrm{R}^{2}$ is essential when using the PLS-SEM technique due to its ability to predict dependent variables and is considered to represent a measure of predictive value [3]; likewise indicates the explained variance of the endogenous variables by exogenous variables, the values are in the range from 0 to 1 , so between more high value results indicate greater prediction accuracy. Authors such as $[49,66]$ recommend a value of $0.75,0.50,0.25$, considering it substantial, moderate and weak. While [12], suggesting .67, .33, .10 considering the same criteria (substantial, moderate and weak). [63, 3].

Table 9 Coefficient of determination R

\begin{tabular}{|l|c|c|c|}
\hline & R square & Adjusted R squared & \\
\hline Contact & 0.072 & 0.069 & Very weak \\
\hline Efficiency_ & 0.590 & 0.589 & Strong \\
\hline Fulfillment / reliability_ & 0.343 & 0.341 & Moderate \\
\hline Guaranty_ & 0.201 & 0.199 & Weak \\
\hline Privacy & 0.180 & 0.177 & Weak \\
\hline Responsiveness_ & 0.221 & 0.219 & Weak \\
\hline
\end{tabular}

Therefore, the $\mathrm{R}^{2}$ prediction of the Contact constructs whose result of $6 \%$ is below the minimum value recommended by the authors, therefore, it is considered that the effect and relationship it has on the CSEM is minimal; Likewise, the Responsiveness variables with $21.9 \%$ Guarantee $19.9 \%$ and Privacy $17.7 \%$ show a weak relationship, so the effect of these variables with the CSEM is reduced, likewise the Compliance / Reliability variable with $34.1 \%$ shows a moderate relationship and effect, while the Efficiency variable with $58.9 \%$ and a strong relationship and therefore an important effect on the CSEM. It is relevant to mention that in the same way we can carry out a more detailed analysis of each item that makes up each construct and see the effect that each one generates on the construct.

\subsubsection{Size effect $F^{2}$ (Effect size $f^{2}$ )}

Table 10 Results of F 2

\begin{tabular}{|c|c|c|c|c|c|c|c|}
\hline & CSEM & Contact & Efficiency_ & $\begin{array}{l}\text { Fulfillment / } \\
\text { reliability_ }\end{array}$ & Guaranty_ & Privacy & Responsiveness_ \\
\hline CSEM & & 0.078 & 1,440 & 0.522 & 0.252 & 0.219 & 0.284 \\
\hline Contact & & & & & & & \\
\hline Efficiency_ & & & & & & & \\
\hline $\begin{array}{l}\text { Fulfillment } \\
\text { reliability_ }\end{array}$ & & & & & & & \\
\hline Guaranty_ & & & & & & & \\
\hline Privacy & & & & & & & \\
\hline Responsiveness & & & & & & & \\
\hline
\end{tabular}


The effect size allows evaluating and observing the effect of each construct / exogenous variable in a construct / endogenous variable as indicated by [63], likewise according to [67], who indicates that the range of values to evaluate f are: 0.02 (small effect), 0.15 (medium effect), 0.35 (large effect). As can be seen in Table \#, five variables have a large effect on the CSEM, being Efficiency the one that presents the greatest positive effect on the CSEM, however, the Contact variable has a value that represents a small (positive) effect, which indicates, therefore, it indicates that its effect for the buyer is minimal when evaluating the CSE in Mexico.

\subsubsection{Predictive relevance $Q^{2}$ (Blindfolding and Predictive Relevance $Q^{2}$ )}

The predictive relevance criterion is recommended by authors such as Hair et. al. [49-39] in research as an additional precision criterion to $\mathrm{R}^{2}$. For which it is recommended to apply the Stone-Geisser's $\mathrm{Q} 2$ value test [68, 69]. This measurement is an indicator obtained in SmartPLS using the procedure blindfolding, the values set by [12], and [49], are: 0.02 (small), 0.15 (media) and 0.35 (major) with which estimates the predictive validity of the model. Therefore, values greater than 0 have relevance in the predictions for an endogenous construction, values below zero indicate a lack of predictive relevance. [3].

Table 11 Q2 Results

\begin{tabular}{|l|c|c|c|}
\hline & SSO & SSE & $\mathbf{Q}^{\mathbf{2}}$ (= 1-SSE / SSO) \\
\hline CSEM & 316,000 & 316,000 & \\
\hline Contact & 948,000 & 899,573 & 0.051 \\
\hline Efficiency_ & 3792,000 & 2491,878 & 0.343 \\
\hline Fulfillment / reliability_ & $1,264,000$ & 971,593 & 0.231 \\
\hline Guaranty_ & 948,000 & 814,223 & 0.141 \\
\hline Privacy & 632,000 & 543,476 & 0.140 \\
\hline Responsiveness_ & $1,264,000$ & 1064,790 & 0.158 \\
\hline
\end{tabular}

Source: Own preparation with information PLS-SEM

In table 11, it can be seen that the variables Privacy (with a value of 0.140 ), Guarantee (with a value of 0.141 ), Responsiveness (with a value of 0.158), and Compliance / Reliability have an average prediction for the model, while Efficiency (with a value of 0.343 ) has a large predictive capacity; while the Contact variable has a value of 0.051 which is considered a low prediction to estimate the predictive validity of the structural model.

\subsubsection{Effect size $q^{2}$ (Effect size $q^{2}$ )}

The $q^{2}$ effect makes it possible to evaluate how an exogenous construct / variable helps a value of an endogenous $\mathrm{Q}^{2}$ variable or construct as a measure of predictive relevance; the range of values 0.02 (small), 0.15 (medium), 0.35 (large). The calculation is carried out manually, since the SmartPLS software does not generate it as indicated [32, 3, 63], the calculation is carried out using the formula $q 2=\left(\mathrm{Q} 2\right.$ included- $Q 2$ excluded) / ( $1-\mathrm{Q}^{2}$ included).

\subsection{Fitting the global RSMR model}

The fit of the model is generated and checked using the mean square residual (RSMR) as recommended [70, 71], Henseler et al. [37], A Raza [54], which recommend considering a model with a good fit if its value is less than 0.08 . Therefore, if the SRMR value is zero, it would indicate a perfect fit, while a model with values above 0.06 is correct [37].

\section{Conclusion}

With the application of the case study, it was possible to verify that the application of the PLS-SEM technique in an investigation allows the researcher to build their models, which are originated from the existing theory, and in this way, check possible relationships between constructs and therefore the verification of their hypotheses; Therefore, with the results obtained, through the analysis carried out with the PLS-SEM technique, it allows the researcher to propose an extension of the existing theory. Therefore, it is considered relevant-fundamental to generate a model that serves as a guide for researchers who are starting to use this technique. Which is shown in Figure 5. 


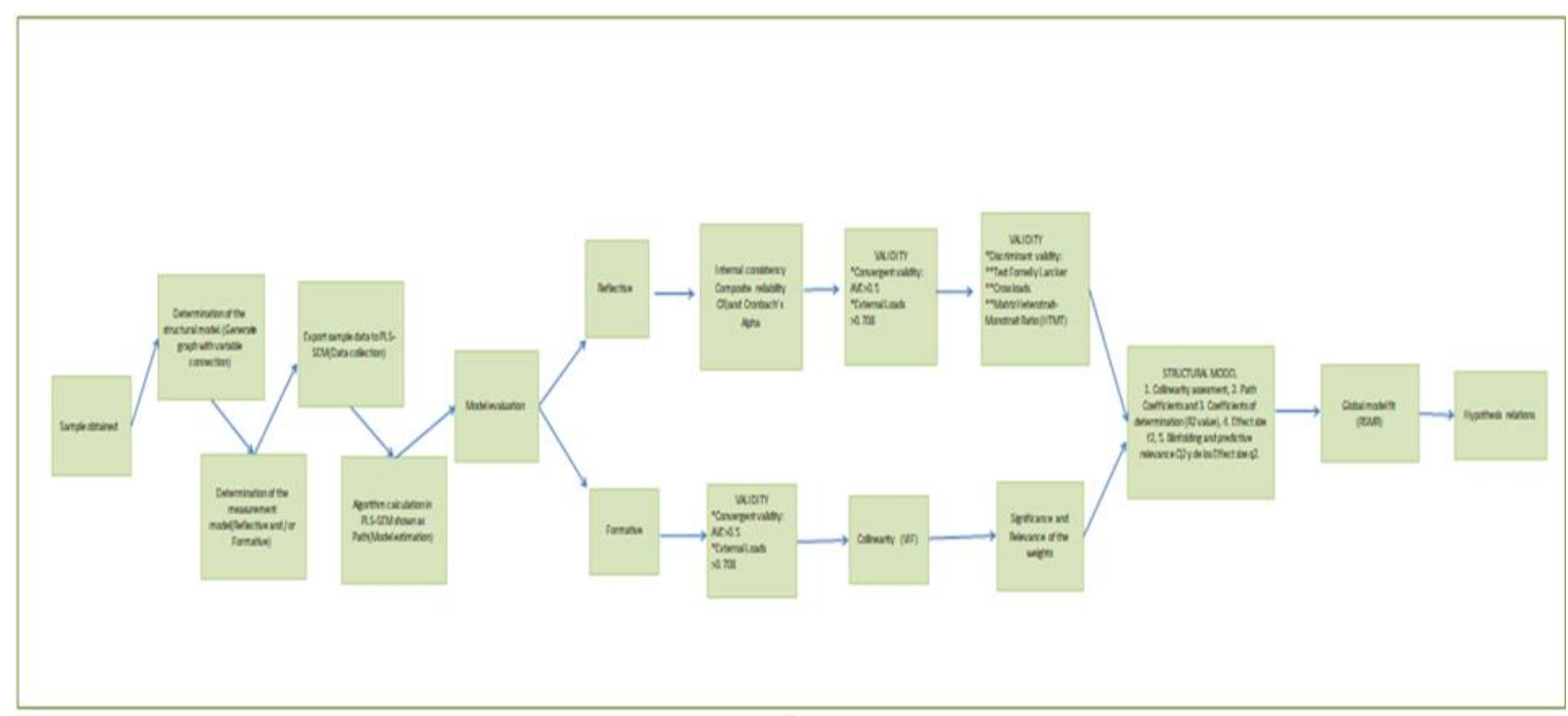

Figure 5 Proposed model to apply PLS-SEM; Source: Own preparation

With the above it can be concluded that PLS-SEM is a technique that its benefits can be considered ease of use which is relevant to researchers who initiate use of the technique, so it or for those who decide to use this technique in its investigations due to the characteristics that this technique requires for its application (sample size, data types , etc.). It is also important to mention that the way in which the results of the analyzes are presented is simple, which allows the researcher to analyze them, and if necessary to be able to make decisions (design or adjustments).

\section{Compliance with ethical standards}

\section{Acknowledgments}

Thanks are extended to the Popular Autonomous University of the State of Puebla, for its contributions to the knowledge for this publication.

\section{Disclosure of conflict of interest}

There is no conflict of interest declared on this research article.

\section{References}

[1] Ghasemy M, Teeroovengadum V, Becker JM, Ringle C. This fast car can move faster: a review of PLS-SEM application in higher education research, Springer Nature BV. 2020; 80: 1121-1152

[2] Haenlein M, Kaplan A. A Beginner's Guide to Partial Least Squares Analysis. Understanding Statistics. 2004; 3(4): 283-297.

[3] Martínez M, Fierro E. Application of the PLS-SEM technique in knowledge management: a practical technical approach, Ibero-American Journal for Research and Educational Development. 2018; 8(16): 1-35.

[4] Leyva O, Olague J. Structural equation model by the partial least squares (PLS)method. ResearchGate. 2014; 480497.

[5] Olea D, Aldrette A, Cuautle L, Reyes M. e-SQ Systematic literature review: A model proposal for Mexico as an effect of the Covid-19 contingency. Global Journal of Engineering and Technology Advances. 2020; 5(3).

[6] Lohmoller JB. Latent Variable Path Modeling with Partial Least Squares. Physica-Verlag, Heidelberg. 1989.

[7] Bentler P, Huang W. On Components, Latent Variables, PLS and Simple Methods: Reactions to Rigdon's Rethinking of PLS . Elsevier. 2014; 47(3): 138-145.

[8] Dijkstra TK, Henseler J. Consistent Partial Least Squares Path Modeling, MIS Quarterly. 2015; 39(2): 297-316. 
[9] Salgado L, Espejel J. Analysis of the study of causal relationships in marketing. Innovar Magazine. 2015; 26(62): 79-94.

[10] Wold H. Soft modeling - The basic design and some extensions. In K. Jöreskog \& H. Wold (Eds.). Systems under indirect observation ll (1-53). Amsterdam: North-Holland Press. 1982.

[11] Wold H. Partial Least Square. In S. Kotz \& NA Johnson (Eds). Encyclopedia of Statistical Sciences. 1985; 6: 581591.

[12] Chin WW. The Partial Least Squares approach to Structural Equation Modeling. In GA Marcoulides (Ed.). Modern Methods for Business Research (295-358) Mahwah, NJ: Lawrence Erlbaum Associates, Publisher. 1998.

[13] Chin WW. Partial Least Square for researchers: An overview and presentation of recent advances using the PLS approach. 2000.

[14] Medina R. Market orientation and innovation, as sources of competitive advantage: analysis of the hotel sector in Ciudad Juárez, [Ph.D. dissertation]. Autonomous University of Ciudad Juárez Institute of Social Sciences and Administration. 2015; 125-146.

[15] García M. Causal analysis with structural equation of citizen satisfaction with services municipales.Proyecto so Master. University of Compostela. Spain. 2011.

[16] Ruiz M, Prado A, San Martín R. Structural equation model. Roles of the psychologist. Faculty of Psychology . Autonomous University of Madrid. 2010; 31(1): 34-45.

[17] Hair JF, Sarstedt M, Ringle CM, et al. An assessment of the use of partial least squares structural equation modeling in marketing research. Journal of the Academy of Marketing Science. 2012; 40: 414-433.

[18] Hair JF, Sarstedt M, Pieper TM, et al. The use of partial least squares structural equation modeling in strategic management research: a review of past practices and recommendations for future applications. Long Range Planning. 2012; 45: 320-340.

[19] Ringle CM, Sarstedt M, Straub DW. Editor's comments: a critical look at the use of PLS-SEM in MIS quarterly. MIS Quarterly. 2012; 36: iii - xiv.

[20] Hair J, Hollingsworth CL, Randolph AB, et al. An updated and expanded assessment of PLS-SEM in information systems research. Industrial Management \& Data Systems. 2017; 117: 442-458.

[21] Richter NF, Sinkovics RR, Ringle CM, et al. A critical look at the use of SEM in international business research. International Marketing Review. 2016; 33: 376-404.

[22] Ringle CM, Sarstedt M, Mitchell R, et al. Partial least squares structural equation modeling in HRM research. The International Journal of Human Resource Management (forthcoming). 2019.

[23] Peng DX, Lai F. Using partial least squares in operations management research: a practical guideline and summary of past research. Journal of Operations Management. 2012; 30: 467-480.

[24] Kaufmann L, Gaeckler J. A structured review of partial least squares in supply chain management research. Journal of Purchasing and Supply Management. 2015; 21: 259-272.

[25] Lee L, Petter S, Fayard D, et al. On the use of partial least squares path modeling in accounting research. International Journal of Accounting Information Systems. 2011; 12: 305-328.

[26] Nitzl C. The use of partial least squares structural equation modeling (PLS-SEM) in management accounting research: directions for future theory development. Journal of Accounting Literature. 2016; 37: 19-35.

[27] Do Valle PO, Assaker G. Using partial least squares structural equation modeling in tourism research: a review of past research and recommendations for future applications. Journal of Travel Research. 2016; 55: 695-708.

[28] Ali F, Rasoolimanesh SM, Sarstedt M, et al. An assessment of the use of partial least squares structural equation modeling (PLS-SEM) in hospitality research. International Journal of Contemporary Hospitality Management. 2018; 30: 514-538.

[29] Usakli A, Kucukergin KG. Using partial least squares structural equation modeling in hospitality and tourism: Do researchers follow practical guidelines? International Journal of Contemporary Hospitality Management. 2018; 30: 3462-3512.

[30] Sarstedt M, Ringle C, Hwa-Cheah J, Ting H, Moisescu O, Radomir L. Structural model robustness checks in PLSSEM. Tourism Economics. 2019; 1-24. 
[31] Hernández- Sampieri R, Fernández-Collado C, Baptista-Lucio P. Research methodology. Bogota: McGraw-Hill. 2007.

[32] Hair JF, Matthews L, Matthews R, Sarstedt M. PLS-SEM or CB-SEM: updated guidelines on which method to use. Int. J. Multivariate Data Analysis. 2017; 1(2): 107-123.

[33] Ruiz A, Pardo A, San Martín R. STRUCTURAL MODEL EQUATIONS papers Psychologist. 2010; 31(1): $34-45$.

[34] Manzano AP. Introduction to structural equation models. Research in Medical Education. 2017; 7(25): 67-72.

[35] Gefen D, Straub D, Bordreau M. Structural equation modeling and regression guidelines for research practice. Communications of the Association for information Systems. 2000; 4(7).

[36] Gerbing D, Anderson J. An updated paradigm for scale development incorporating unidimensionality and its assessment. Journal of marketing research . 1988; 25(2): 186-192.

[37] Henseler J, Hubona G, Ray P. Using PLS path modeling new technology research: updated guidelines. Industrial Management \& Data Systems. 2016; 116(1): 2-20.

[38] Shmueli G, Kopplus O. Predictive analytics in information systems research. MIS Quarterly. 2011; 35(3): 553-572.

[39] Hair J, Hult G, Ringle C, Sarstedt M. A Primer on Partial Least Square Structural Equation Modeling (PLS-SEM). United States, California: Sage. 2017.

[40] Salgado L, Y Espejel J. Analysis of the study of causal relationships in marketing, Revista Innovar. 2015; 26(62): 79-94.

[41] Cepeda G, Roldán JL. Applying in practice the PLS technique in business administration. Congress of the Scientific Association of Economics and Business Management. Murcia, Spain. 2004.

[42] Stan V, Saporta G. Customer satisfaction and PLS structural equation modeling. An application to automobile market. ASMDA2005. (756-763). XIth International Symposium on Applied Stochastic Models and Data Analysis. 2005.

[43] Mateos G. Partial least squares (PLS) methods: Origins, evolution, and application to social sciences. Communications in Statistics - Theory and Methods. 2011; 40(13): 2305-2317.

[44] Sarstedt M, Hair JF, Ringle CM, Theile KO, Gudergan SP. 'Estimation issues with PLS and CBSEM: where the bias lies! ', Journal of Business Research. 2016; 69(10): 3998-4010.

[45] Rigdon EE, Becker JM, Sarstedt M. Factor indeterminacy as metrological uncertainty: Implications for advancing psychological measurement. Multivariate Behavioral Research ( forthcoming ). 2019.

[46] Cepeda Carrión G, Henseler J, Ringle CM, et al. Prediction-oriented modeling in business research by means of PLS path modeling. Journal of Business Research. 2016; 69(10): 4545-4551.

[47] Evermann J, Tate M. Assessing the predictive performance of structural equation model estimators. Journal of Business Research. 2016; 69(10): 4565-4582.

[48] Sarstedt M, Ringle CM, Hair JF. Partial least squares structural equation modeling. In: Homburg C, Klarmann M and Vomberg A (eds), Handbook of Market Research, Heidelberg: Springer. 2007; 1-40.

[49] Hair J, Ringle C, Sarstedt M. PLS-SEM: Indeed, a silver bullet. Journal of Marketing Theory and Practice. 2011; 19(2): 137-149.

[50] Máynez A. Organizational knowledge transfer as a source of sustainable competitive advantage: integrating model of factors and strategies. Doctoral Thesis. Doctorate in Strategic Planning and Technology Management, Puebla. 2011.

[51] Valdivieso Taborga and Carlos Eduardo. Comparison of Formative, Reflective, and Antecedents Models of Students Evaluation of Teaching Service, R evist of quantitative methods for the economy and business. 2013; (16): 95-120.

[52] Diamantopoulos A. Formative indicators: Introduction to the special issue, Journal of Business Research. 2008; 61(12): 1201-1202.

[53] Bollen K. Structural Equation with latent variables. United States, North Carolina: John Wilet \& Sons. 1989. 
[54] Raza A, Rather RA, Iqbal MK, Bhutta US. (2020), "An assessment of corporate social responsibility on customer company identification and loyalty in banking industry: a PLS-SEM analysis", Management Research Review. 2020; 43(11): 1337-1370.

[55] Hair JF, Sarstedt M, Ringle CM. Rethinking some of the rethinking of partial least squares, European Journal of Marketing. 2019; 53(4).

[56] Sarstedt M, Mooi E. Regression Analysis. A Concise Guide to Market Research, Springer, New York, NY. 2019.

[57] Ying M, Faraz NA, Ahmed F, Raza A. How does servant leadership foster employees' voluntary green behavior? A sequential mediation model , International Journal of Environmental Research and Public Health. 2020; 17(5): 1792.

[58] Farrukh M, Meng F, Sajid M, Shahzad I. Does strategic fit matter in measuring organizational performance? An empirical analysis, Corporate Social Responsibility and Environmental Management. 2020; 1.

[59] Nunnally Jum C, Ira Bernstein Psychometric Theory, 3d ed., New York: McGraw-Hill. 1994.

[60] Ansari Harahap D, Ratih Hurriyati, Amanah D. A Conceptual Model of E-Service Quality at Branchless Banking in Indonesia, Journal of Internet Banking and Commerce. 2020; 25(2): 1-12 .

[61] Carmines E, Zeller R. Reliability and validity assessment. N. 07-017, Sage University Paper Series on Quantitative Applications the Social Sciences. Beverly, United States: Sage. 1979.

[62] Hair JF, Black WC, Babin BJ, Anderson RE. Multivariate Data Analysis, 7th ed., Prentice Hall, Upper Saddle River, NJ. 2010.

[63] Firdaus B, Ibrahim M, Bin- Razik M. Four Hours Basic PLS-SEM A Step by Step Guide With Video Clips For Student and Scholar. Four Hours Basic PLS-SEM A Step by Step Guide With Video Clips For Student and Scholar. Ipro Publication , 1st, Edition. Malaysia. 2018.

[64] Diamantopoulos A, Siguaw J. Formative versus Reflective Indicators in Organizational Measure Development: A Comparison and Empirical Illustration. British Journal of Management. 2006; 17(4): 263-282.

[65] Kosasi S, Vedyanto, ID Ayu, Yuliani. Boosting E-Service Quality through IT Service Management of Online Stores, 2019 6th International Conference on Electrical Engineering, Computer Science and Informatics (EECSI) , Bandung, Indonesia. 2019; 247-252.

[66] Henseler J, Ringle CM, Sinkovics RR. The use of partial least squares path modeling in international marketing. Advances in International marketing. 2009; 20: 277-320.

[67] Cohen J. Statically power analysis for the behavioral sciences. United States, New York: Laurence Erlbaum Associates. 1988.

[68] Geisser S. A predictive approach to the random effects model. Biometrika. 1974; 61: 101-107.

[69] Stone M. Cross- validatory choice and assessment of statistical predictions. Journal of the Royal Statistical Society. 1974; 36: 111-147.

[70] $\mathrm{Hu} \mathrm{L}$, Bentler P. Fit indices in covariance structure modeling: sensitivity to underparameterized model misspecification. Psychological Methods. 1988; 3(4): 424-453.

[71] $\mathrm{Hu} \mathrm{L}$, Bentler P. Cutoff criteria for fitindexes in covariance structure analysis: conventional criteria versus new alternative. Structural Equation Modeling. 1999; 6(1): 1-55. 